\title{
La influencia de los spots políticos televisivos en la decisión electoral de las mujeres jóvenes universitarias nuevas votantes: México, elecciones federales
}

\author{
Nuria Beatriz Peña Ahumada, Universidad Tecnológica de San Juan \\ del Río, Querétaro, México
}

Resumen: Los spots politicos televisivos han sobresaturado las barras de publicidad comercial. Un gran porcentaje del electorado está compuesto por jóvenes, por lo cual los candidatos y sus estrategas de comunicación y marketing centran sus fuerzas en llegar a este sector. La propuesta de esta investigación radica en incorporar la categoría de género al análisis del proceso de recepción de los spots politicos y la influencia que éstos ejercen en la decisión electoral de las jóvenes universitarias.

Palabras Clave: Proceso de recepción, categoría de Género, mujeres jóvenes universitarias, spots, televisión, mercadotecnia política.

Abstract: Televised political spots have overwhelmed the limits of commercial advertising. A great percentage of the electorate is composed by young people, that's why candidates and their communication and marketing strategies focus their forces to reach this sector. The proposal of this research is based on the incorporation of the gender perspective to the analysis of the political spots' reception process and the influence they have in university young women' electoral decision.

Keywords: Process of reception, gender perspective, university young women, spots and television, marketing politico

\section{Introducción}

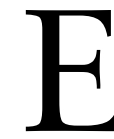

L IMPACTO DE los medios de comunicación en la vida cotidiana, ha trastocado los espacios y al ser mismo, al funcionamiento y transformación de las actividades del mundo, por ello son un fenómeno de gran relevancia que ha sido objeto de estudio del campo de las ciencias de la comunicación y la mercadotecnia.

Tal fenómeno involucra las nuevas formas de los medios masivos de comunicación de compartir, transmitir y difundir información, pero también cómo los individuos recibimos e interpretamos tal información y cómo ésta media en nuestras actividades, acciones y formas de pensar.

Hablar de medios de comunicación es abordar un tema sumamente amplio; sin embargo, el interés de esta investigación radica en el papel de la televisión, un medio de comunicación que permea nuestra vida cotidiana y que se interpone entre la mirada humana y la sociedad, mostrando sus representaciones, proporcionando información y modificando o interviniendo en su forma de ver y nombrar lo que nos rodea.

El objeto de estudio específico son los spots de los candidatos a la presidencia de la república en los comicios electorales de 2006, para determinar cómo éstos pudieron haber

Revista Internacional de Ciencias Sociales

Volumen 1, Número 2, <http://lascienciassociales.com>, ISSN 2530-4909

(C) Global Knowledge Academics. Nuria Beatriz Peña Ahumada. Todos los Derechos Reservados Permisos: soporte@gkacademics.com

Republicado de Revista Internacional de Ciencias Sociales Interdisciplinares 1(2), 2012 (pp. 215-230) 
influido sobre las jóvenes universitarias, las cuales — por razones de edad- ejercían por primera vez su derecho al voto.

Aunado a lo anterior, este trabajo también centra su atención en el derroche de dinero público en las campañas electorales. Las imágenes y mensajes de los candidatos han sobresaturado las barras de publicidad comercialdurante los últimos once años. El costo de las campañas electorales en México supera considerablemente lo que se gasta en otros países: en España, el financiamiento electoral de 2000 fue el equivalente de 50 millones de dólares; en México fue de casi 233 millones (Zuckerman,2006). En las elecciones mexicanas de 1994, "la erogación de los partidos en medios electrónicos representó 24 por ciento de sus recursos, mientras que en 2000 y en 2003 fue poco más de 50 por ciento" (Villamil, 2006, p. 22).

Los datos hablan por sí solos.En los comicios presidenciales del 2000, "los partidos contendientes destinaron alrededor del 55 por ciento de sus recursos a propaganda política en los medios electrónicos, lo que - traducido en dólares - rebasa los 130 millones, y en los últimos comicios - los del 2003 - se alcanzó el mismo porcentaje, en el que los partidos políticos gastaron 662 millones 608 mil 425 pesos en propaganda en radio y televisión" (Vega, 2006, p. 4).

Sin embargo, los datos del Instituto Federal Electoral revelaron que esta proporción se disparó en el 2006 a más del 70 por ciento tan sólo en televisión (IFE, 2006), ya que a un mesde que concluyeran las campañas electorales, "los cinco candidatos presidenciales gastaron 982 millones de pesos en spots para televisión y radio, de acuerdo con los cálculos de la empresa Verificación y Monitoreo" (Villamil, 2006, p.23), cantidad que rebasó totalmente la cifra de lo gastado por todos los partidos en el año 2000.

Es por esto que la presente investigación tiene como línea medular abordar el proceso de recepción aunado al marketing político y la comunicación política, en el contexto de los comicios electorales del año 2006. Tal interacción fue considerada para poder abordar y tratar de entender un fenómeno como lo es la decisión electoral de las mujeres jóvenes universitarias, en su calidad de nuevas votantes, a partir de la recepción de spots políticos televisivos.

Tomando como base estas claves, este trabajo propone el desarrollo de un modelo para el estudio de la recepción televisiva de las jóvenes universitarias, de una manera integral, considerando un ambiente micro y macro que rodea a estas mujeres.

\section{Del objetivo}

Ante esta situación, el objetivo del presente trabajo es el de analizar en torno a las posibilidades de incorporar la categoría de género al análisis de procesos comunicativos. El fenómeno que observa esta investigación es la recepción televisiva de las mujeres universitarias jóvenes como nuevas votantes, respecto al impacto de los spots políticos televisivos sobre su decisión electoral en las elecciones federales del 2006 en México.

\section{De la hipótesis}

El supuesto del que se parte es que laidentidad de género determina las formas particulares en que estas mujeres se relacionan con la realidad social y con sus padres, amigos, compañeros de clase, profesores; en cómo participan en los procesos comunicativos y, en este sentido, 
en cómo se relacionan con la televisión y cómo es que interpretan los spots políticos televisivos.

\section{REVISIÓN DE LA LITERATURA}

\section{Del proceso de recepción televisiva}

Desde la perspectiva de los estudios de recepción, que fue desarrollada por los Estudios culturales y el Análisis crítico de la recepción (Orozco, 1996; Lull, 1990; Jensen, 1987; Morley, 1980, 1986) - , entendemos que lejos de ser la mera representación de una relación causa-efecto (mensaje-receptor) — óptica planteada por la corriente de los efectos-, este fenómeno comunicativo resulta un proceso de producción social de significado (Vega, 2004), llevado a cabo por los miembros de la audiencia, en el que tiene una importancia clave el contexto donde se construye el significado.

El concepto de audiencia considera el reconocimiento de la participación del sujeto, un sujeto al que se le define en una situación socio-histórica, individual y colectiva, determinada y distinta de los otros (Vega, 2005). En este tenor, y de acuerdo con Guillermo Orozco (1996), la audiencia resulta no una entidad homogénea, sino un mosaico de sujetos diferenciados por su género, edad, capital económico, cultural, educativo, por su etnia y por sus intereses concretos, entre otras variables. Lo que Orozco no niega es que a estas audiencias, o comunidades, las define su pertenencia sociocultural.

Por lo tanto, esta definición conceptual del término audiencia constituye una de las claves aportadas por la corriente del análisis crítico, en tanto que ha permitido reconocer la capacidad de acción del sujeto y explorar empíricamente su poder para hacer, al mismo tiempo, un uso social de los medios, consumir y decodificar los mensajes. Al mismo tiempo, este concepto permite diferenciar al sujeto del concepto clásico de receptor, al que hacía alusión la perspectiva de los efectos donde deriva la propuesta de la "aguja hipodérmica", desde la cual se le definía como un objeto pasivo que no tomaba parte del proceso de recepción, más que como destinatario del mensaje (Vega, 2004).

Por ello para Jensen (1992) el análisis crítico asume el proceso de recepción como una relación entre audiencia y contenido; por tanto, se ha centrado en analizar procesos concretos en los cuales los discursos mediáticos se encuentran con las prácticas culturales de los sujetos.

\section{Televisión y audiencias}

La televisión es en la actualidad uno de los más importantes medios de comunicación, de mayor alcance e impacto en la sociedad, "independientemente del estrato social al que se pertenezca; incluso, la edad, ya que se trata de un medio que preferentemente está en los hogares incidiendo en los miembros de la familia desde la más tierna infancia" (Bustos, 1999, p. 24).El papel de este medio es relevante en la cotidianidad de las personas (Vega, 2004), y es aquí donde radica la razón del porqué se ha escurrido en la red de la investigación académica de la comunicación y del marketing político (Silverstone, en Morley, 1992).

Barbero (1987) y Silverstone (1996) han señalado que el aparato televisivo constituye una noción de cultura, como una forma de práctica cultural; dicho proceso comienza en el seno familiar, en nuestro hogar, lugar que se constituye como el ambiente primario de interacción con la televisión (Morley, 1996). 


\section{De las mujeres y su relación con la televisión}

Para el enfoque de los estudios de recepción en el que se inscribe el presente trabajo, ser hombre o ser mujer conlleva diversas implicaciones, tanto en la percepción general como en la individual. En referencia a esto, Orozco (1987) ha señalado que desde muy pequeños vamos desarrollando lo que se ha llamado el patrón mental del género, que es precisamente un patrón mental que influye la percepción masculina y femenina.

Tomando en cuenta la importancia de la relación del espacio privado y la mujer, y retomando la idea de que el hogar es el ambiente primario donde se lleva a cabo el proceso de recepción con el televisor, diversos autores - con perspectiva feminista - han coincidido que entre las mujeres y la televisión existe una relación constante, de compañía, que cumple una función dentro de sus vidas (Bustos, 1992).

En la serie de trabajos que Lull (1988) realizó en Estados Unidos, Inglaterra, Alemania, India y — el más conocido - en China, explica que los tipos de sistemas económico-políticos de cada nación no parecen tener influencia alguna; sin embargo, "en todas partes, los hombres parecen preferir deportes, programas de acción y programas informativos (especialmente, noticias), mientras que las mujeres prefieren los dramas (incluyendo series, telenovelas y películas) y programación basada en música danza y comedia" (Lull, 1988, p.248).

De acuerdo con Morley (1992), los hombres favorecen los noticieros nacionales, mientras que las mujeres muestran más interés por los noticieros locales, con una característica muy especial: prestan poca atención a la información, a causa de las labores domésticas.

La preferencia por uno u otro tipo de programación denota estereotipos de lo que es propio del hombre y la mujer. Estos estereotipos, a su vez, resultan de la propia educación diferenciada de la que los adultos hemos sido objeto, según hayamos nacido hombres o mujeres (Durkin, 1985).

\section{Los jóvenes y su relación con la televisión}

Actualmente la televisión e internet se han convertido en los medios idóneos para sostener interacciones personales. Los jóvenes los han hecho parte de su vida, como la mayoría de la población; por ellos se comunican, por ellos se informan y con ellos encuentran su diversión: los grandes compañeros de todo momento.

Según la Encuesta Nacional de Juventud 2010 - aunque no sea posible afirmar que los circuitos tradicionales tales como la familia, los amigos, los vecinos, hayan perdido centralidad-, la mayor parte de la información que manejan los jóvenes proviene de la televisión. La televisión es el medio de comunicación que los jóvenes más consumen; especialmente, las mujeres jóvenes. En segundo lugar se encuentra la radio, seguida de la prensa e internet.

Grandi (1995) señala que los jóvenes ven la televisión en función de la modalidad mediante la que quieren integrar dicho ver en su vida cotidiana.Pocas veces se trata de una recepción solitaria; más bien se lleva a cabo para mantener y reforzar sus relaciones sociales.

\section{De los spots políticos televisivos}

Poca literatura refiere de manera precisa el término de spot político; generalmente se ahonda sobre el término spot publicitario. Sin embargo, para fines de este trabajo se define como "un proceso de comunicación por el cual una fuente - partido o candidato- compra la 
oportunidad de exponer a la audiencia mensajes políticos a través de medios masivos, con la intención de influir en sus actitudes o conductas políticas" (Kaid, 2001, p. 250).

Una segunda definición es aquella que los entiende como "mensajes políticos televisivos de campaña, persuasivos, construidos por los propios partidos y no mediatizados por los medios de comunicación" (Beauduox, 2005).

Ambas definiciones recurren a describir aspectos generales del spot tales como el emisor, su carácter de mensaje, carácter persuasivo, intención de influencia en las actitudes de una audiencia.

Estos mensajes, en lugar de presentar programas elaborados y estructurados, se caracterizan por ser mensajes sencillos, cortos, concretos con slogans o frases que sean fáciles de recordar por el ciudadano y, sobre todo, apoyándose en la imagen más que en el argumento. "Se sustituye el debate sustantivo sobre los problemas sociales, por promesas no fiscalizables, por logros virtuales y por acusaciones mutuas" (Vega, 2006, p. 5), que en nada fortalecen la democracia. Se puede considerar que los spots son espacios publicitarios cuya producción es destinada a la persuasión del electorado, más que a una información objetiva. Es decir, su finalidad es reactivar una predisposición positiva hacia el candidato que aparece en la pantalla.

Hasta aquí se han abordado, dentro de la revisión de la literatura, los aspectos fundamentales para el estudio en el que se centra esta investigación. En los siguientes apartados se realiza la revisión de lo referente a las participantes de este estudio.

\section{La concepción de ser joven}

Hablar de juventud no es fácil; menos aun, cuando dicho concepto se utiliza de forma tan generalizada (y a la ligera), como si los jóvenes fuesen un grupohomogéneo con pensamientos, ideas y comportamientos comunes. Es una etapa en sí "que encierra experiencias nuevas, aprendizajes, frustraciones, adaptaciones o inadaptaciones, al contexto social en el cual viven y se desarrollan" (Franco, 2000, p. 109).

Cuando se habla de jóvenes, se ha de tener clara conciencia de la considerable diversidad de nociones que existen sobre juventud en relación con las distintas sociedades, los diversos contextos espacio-temporales, e incluso sus modificaciones a lo largo del tiempo en un medio concreto, sus diversas condiciones sociales y culturales.

Para poder hablar de juventud es necesario tomar en cuenta que cada país tiene definiciones distintas; cada clase social, cada tradición cultural, étnica, religiosa o lingüística tiene definiciones diferentes (Dávila, 2005). Por lo tanto, no se puede lograr una definición absoluta, ya que lo que se define como juventud dependerá de las experiencias de vida; es decir, estará en función de qué es lo hacen las personas en ese período de tiempo, por lo cual la definición puede variar.

En lo que corresponde a la Organización de las Naciones Unidas (ONU) en el ámbito internacional; el Instituto Nacional de Estadística, Geografía e Informática (INEGI), en México, y la Encuesta Nacional de la Juventud 2000,se entiende por juventud "al grupo de población que tiene de 15 a 29 años de edad", como definición instrumental y de carácter operativo. Como se puede observar, ésta sería la noción más general y usual de este término, el que se refiere a una franja de edad, un período de vida, "caracterizada por múltiples cambios biológicos, psicológicos, sociales y culturales” (Ehrenfeld y Fernández, 2003, p. 70), cuando éste abandona la infancia para procesar su entrada en el mundo adulto. 
Es necesario mencionar que abordar a la juventud como una categoría etaria es válido en una primera instancia. Sin embargo, tal como se ha señalado líneas arriba, la noción de juventud es socialmente variable en los contenidos y significados sociales; "esos procesos se modifican de sociedad en sociedad y, en la misma sociedad, a lo largo del tiempo y a través de sus divisiones internas" (Abramo, 1994, p.1). Por ello se puede determinar que por sí sola la categoría etaria no es suficiente para el análisis de lo juvenil (Dávila, 2005), pero sí es necesaria para marcar algunas delimitaciones iniciales y básicas.

De igual forma, se habla de la perspectiva antropológica-cultural, la cual "relevaba la influencia sobre los jóvenes del contexto sociocultural donde se socializan" (Gurrieri y TorresRivas, 1971, p. 30); es decir, existe un reconocimiento de sí mismo en un colectivo mayor, en un grupo social que define y que determina el compartir una situación común de vida y convivencia. La identidad refiere obligatoriamente al entorno, al ambiente. Los contenidos que originan la identidad generacional implican modos de vida, particularmente prácticas sociales juveniles y comportamientos colectivos, en los cuales se involucran valores y visiones de mundo que guían esos comportamientos, debido a que comparten experiencias históricas parecidas (Dávila, 2005; Fernández, 2000).

Por ello y para poder lograr un acercamiento más fiel a las participantes de esta investigación, se ha considerado la propuesta que a continuación se señala:

Se retoma la propuesta de praxis divergente de Roberto Brito (2002), con la que la existencia juvenil adquiere significación a partir del momento en que se establece una diferenciación cultural con los demás sujetos sociales, y es precisamente a través de su praxis como logra distinguirse socialmente y adquirir un significado; "ésta distinción se logra cuando el sujeto juvenil establece su diferenciación, más allá de los aspectos estrictamente biológicos o de edad" (p. 44). De igual forma, los jóvenes se reconocen y se identifican entre sí, al establecer una diferenciación existencial con los demás resignifican los valores, conceptos y mensajes del ser y estar en el mundo; y esto va a depender de su adscripción socioeconómica, de género, etnia y de identidad sexual, generando una praxis diferenciada (Reguillo, 2000).

\section{El ser mujer y el ser joven}

A lo largo de la historia se ha tendido a asociar el concepto de jóvenes con los varones, teniéndose menos información y reflexión sobre las particularidades de género y los procesos que experimentan las mujeres. Así, pues, además de la incompletitud que encierra la definición de joven o adolescente, existe una gran ausencia de las mujeres en la comprensión de este campo (Ramos, 2000). Es por ello que unade las principales modificaciones que se han realizado al concepto de hombre joven "es la de incorporar, desde todas las perspectivas, el de mujer joven" (Ehrenfeld, 2003, p.76).

Derivado de una revisión de bibliografía e investigaciones referentes a la temática de la mujer joven, entendemos que es necesario unconcepto que identifique a la mujer desde una perspectiva juvenil, ya que posee una diversidad de características que la diferencian del sexo opuesto, lo que implica dejar a un lado la tradicional tesis de que las distinciones entre hombres y mujeres se originaban solamente en las diferencias biológicas de los sexos (Lamas, 2000). 


\section{Jóvenes universitarios}

Algunas de las aseveraciones que se han realizado con respecto a la categoría de jóvenes universitarios deben tomarse con cierto cuidado, sobre todo porque "la población juvenil universitaria puede ser sumamente heterogénea, debido fundamentalmente a las notables diferencias socioculturales regionales que imperan en México" (De Garay, 2003, p. 45), lo que impide, en muchas ocasiones, generalizar para el conjunto de la juventud universitaria. A pesar de ello, en este sector sí podemos encontrar ciertas características que los pueden identificar, tales como:

1. Los jóvenes que se incorporan como estudiantes a los recintos de educación superior forman parte de un grupo social específico, al ocupar una posición y una función social determinada por su paso en la institución de socialización más importante después de la familia: la escuela. Se trata de sujetos sociales que conforman una élite, ya que la gran mayoría de los jóvenes mexicanos no logran acceder a dicho nivel educativo (Portillo, 2003).

2. La juventud que ingresa a las universidades e institutos de educación superior "han invertido, al menos, doce años de su corta vida en el aprendizaje de saberes", por lo que se puede decir que cuentan así con una historia escolar exitosa" (De Garay, 2002, p. 248).

3. Es importante indicar que con los estudios superiores se agudiza el espíritu crítico de los jóvenes; es decir, se considera a la universidadcomo la institución que eleva la crítica, el sentido democrático y socialista (Fernández, 2003).

Las experiencias de socialización que viven los alumnos son diferentes por estar en distintos tipos de institución.Los jóvenes estudiantes de la educación superior se diferencian por el tipo de conocimientos que construyen cotidianamente; por las expectativas educativas, profesionales y sociales que se invierten durante una carrera de años variables; por el tipo de trayectoria que involucra distintas estrategias de vida, de estudio y aprendizaje, y por el tipo de identidad específica que se construye a lo largo de los estudios superiores (Reguillo, 2000). En México, la expansión y desarrollo del nivel educativo superior es muy reciente; data de los últimos treinta años (De Garay, 2004).Específicamente, en el caso de las mujeres, su acceso al sistema de enseñanza formal se ha incrementado en los últimos decenios. Sin embargo, el análisis de la composición por género es indispensable para observar uno de los rasgos de diferenciación más significativos entre los estudiantes de la moderna universidad (Chaín, 1995).

Así, estas construcciones sociales de lo que es ser joven y universitaria definiráncómo se relacionan estas mujeres con la realidad social, en las esferas doméstica y pública, y - para el tema particular de análisis - cómo se relacionan con la televisión y con los mensajes que ésta produce; especialmente, los spots políticos.

\section{MÉTODO}

La presente investigación fue elaborada desde la propuesta de los estudiosde recepción y audiencias, ya que se consideró que sus fines metodológicos, teóricos y epistemológicos se adecuan a los objetivos planteados. El modelo de análisis de recepción que permitió acercarnos 
al objeto de estudio es elanálisis integral del proceso de recepción televisiva propuesto por Vega (2004).Tal modelo ayudó a entender el proceso de recepción de las mujeres jóvenes universitarias, nuevas votantes, ya que no sólo toma en cuenta al mensaje —al spot televisivo en sí-, sino que permite comprender a las participantes del estudio como individuos situados sociohistóricamente, diferenciadas de los otros, y las cuales —en suindividualidad y contexto- tienen una diversidad de factores que median el significado que el sujeto construye a partir de la recepción de los mensajes televisivos (Vega, 2005).

El método utilizado para esta tesis es el cualitativo.Dicha elección obedece a coincidir con la llamada investigación de segundo orden (investigar desde dentro), pretendiendo acercarme lo más posible a un acertado y reflexivo análisis de los objetivos que se han propuesto para esta investigación.

La estrategia metodológica ha considerado al grupo de audiencia de mujeres jóvenes con rangos de edad entre 18 y 24 años, primeras votantes y que eran estudiantes de la Universidad Tecnológica de San Juan del Río, Querétaro. La elección de la institución parte de la facilidad de acceso y cercanía que se tuvo respecto a las jóvenes, lo cual ha sido primordial para la investigación.

Se consideró trabajar con mujeres que pertenecieran a tres niveles socioeconómicos, cuya categorización se realizó con base en el ingreso mensual de su familia.Para ello nos basamos en la propuesta de clasificación que hace la Asociación Mexicana de Agencias de Investigación de Mercados y Opinión Pública (AMAI), en cuanto a niveles socioeconómicos se refiere, quedando de la siguiente manera:

- Grupo 1.Denominado como "clase baja", con un ingreso mensual familiar deunmínimo de 2,700 a 6,799 pesoscomo máximo.

- Grupo 2.Clase media, con un ingreso mensual por familia que va de un mínimo de 6,800 pesos y un máximo de 11,599.

- Grupo 3. Clase alta, con un ingreso mensual por familia que va de 11,600 pesos a un máximo de 34,999.

Derivado de que no se buscó cuantificar el fenómeno, la herramienta metodológica seleccionada fue el grupo de discusión. Se decidió el empleo de esta técnica porque su dinámica permite que fluya la conversación grupal de manera natural, lo que posibilita conocer las opiniones de las participantes tal como las vierten en un espacio natural, frente a otras jóvenes con características similares, a través de todo lo cual pueden coincidir en la temática o diferir en algunos aspectos.

Esta herramienta permitió la posibilidad de entender la complejidad de este tema de investigación en las palabras de las propias mujeres jóvenes universitarias.

Se organizaron cuatro grupos de discusión por nivel socioeconómico, hasta que se logró la saturación de datos, aspecto fundamental en la investigación cualitativa. 


\section{RESULTADOS}

\section{De su perspectiva e identidad como mujeres y jóvenes}

La mayoría de las participantes de esta investigación coincidieron en identificarse y definirse primero como jóvenes y colocar en segundo lugar su condición de género, es decir: identificarse como mujeres (Aramburu, 1984; Lagarde, 2007; Cob, 2007).

Tal como se mostró en la vitrina metodológica, las participantes pertenecen a diversos niveles socioeconómicos; las jóvenes de clase alta y media consideran a la juventud como una etapa que les permite tener distintas condiciones de vida y que ellas interpretan como la carencia de responsabilidades y preocupaciones, tal como lo señala Lagarde (2000).

Los jóvenes no nos tomamos las cosas tan en serio.Hay muchas cosas que aún no me siento en la edad de preocuparme, a diferencia de una mujer (G2).

Considero que el ser joven te permite tener diferentes ideologías y diferentes intereses a los que tiene una mujer. Al igual, yo tengo necesidades diferentes, por ejemplo, a las que tiene mi mamá. Yo quiero conocer, viajar, divertirme, y mamá, pues no. Para mí es muy diferente ver las cosas como una joven que como una mujer; son etapas muy diferentes (G3).

Sin embargo, dicha opinión no se presentó en el grupo de jóvenes de clase baja, quizá porque su condición socioeconómica les exige trabajar para poder pagar sus estudios, y por lo tanto consideran a la escuela y su trabajo extradoméstico como responsabilidades.

Me divierto como joven, pero eso no me exenta de tener responsabilidades, no sé si igual o un poquito menos que mis papás, ya que también tengo que trabajar y estudiar; si no, cómo pago mis inscripciones y libros, por ejemplo (G1).

¿Estas jóvenes consideran que existen diferencias entre ellas y otras mujeres? En general las universitarias sí se perciben diferentes a otras mujeres. Tal diferencia radica en las distintas necesidades que cada grupo de mujeres puede tener. Asimismo se consideran como un grupo privilegiado por tener acceso a la universidad, espacio que — según ellas - las dota de conocimientos con los que pueden tomar decisiones más acertadas.

Yo creo que encontramos una principal diferencia con aquéllas que no han estudiado, que no han tenido la oportunidad de estudiar, claro, porque nos preparamos más, hacemos otras cosas; no cuidamos niños, no hacemos aseo de la casa, ;uy! No (G2). Yo lo viví en mi casa, con mi mamá, que se dedica al hogar.Y, bueno, cuando se acercaba la fecha de la elección me preguntópor quién iba a votar; yo le dije lo que proponía cada candidato.Por eso te digo que sí afecta, ya que el ser universitaria te permite estar más cercana de este tipo de información, ya sea porque nos hablan del tema y te acercan a ellos.Por ejemplo, cuando se habla de aranceles, mucha gente que no estudia dice ¿qué es eso? Y pues uno que sí tiene la oportunidad de estudiar, pues tienes más nociones sobre ese tema $(G 3)$. 


\section{De cómo votan}

El voto de las jóvenes universitarias es determinado por la persona; es decir, para ellas fue importante la actitud del candidato: buscan una actitud con la que ellas se identifiquen.

Cuando yo voto me fijo en la persona; por ejemplo, cuando los candidatos tienen una fama que no y, pues, por ejemplo,Felipe Calderón no la tenía; él apenas iba empezando y yo voté por él (G2).

La mayoría de las jóvenes reconoce que la decisión de su voto se da a partir de las propuestas que los candidatos emiten,propuestas donde ellas se ven contempladas o tomadas en cuenta. Ponen de ejemplo los spots televisivos que aparecieron con propuestas muy enfocadas al sector juvenil, como las referentes a oportunidades de empleo, seguro social para recién egresados de las universidades y con respecto a las mujeres; también las propuestas referentes a través de spots televisivos guarderías, trabajo, etcétera. Al parecer estos spots hicieron que las jóvenes universitarias se sintieran tomadas en cuenta

El que las jóvenes universitarias pudieran ejercer su voto significó que se sintieran tomadas en cuenta; es decir, se presenta el fenómeno donde se manifiesta como una característica del sector juvenil, precisamente, el sentimiento de exclusión por parte de la sociedad. Y al momento de llevar a cabo una actividad que consideran importante como ciudadanas, las hace sentirse parte de la toma de decisiones, que son consideradas, que son parte del espacio público, espacio de donde se sienten relegadas por su doble condición: mujer y jóvenes.

Al principio sí me sentí bien, porque mi opinión va a ser tomada en cuenta ... Yo me siento bien conmigo, porque puede hacer buenos cambios (G1).

Significó que no te hicieran a un lado, que supieran que a nosotros también nos interesa nuestro país (G2).

\section{El hogar: primera comunidad de recepción}

El agente de socialización política primario es la familia; es decir, el lugar y las personas con las que suele hablar de política, de generar opiniones. En el caso de las jóvenes de clase media y, en especial, de clase alta, esta situación es así. Expresaron que las personas con quienes suelen hablar de política son algunos miembros de su familia. Y nuevamente este hallazgo nos permite confirmar la importancia que pueden tener las opiniones realizadas por el género masculino para las jóvenes universitarias, en cuestión de política. Son a los integrantes hombres a quienes consideran conocedores e interesados en lapolítica.

A mi hermano mayor le gusta mucho leer el periódico. Es con el que hablo más. Es el que se interesa, se informa y lee más sobre eso, y por eso es con él con quien platico de política; poquito, pero sí, sí platico (G2).

Por ejemplo, en mi caso, mi papá es muy arraigado, muy afín a la política; le gusta mucho la política.Por eso a mí me interesa, porque luego hasta me pregunta ¿y tú qué piensas de esto? Me gusta dialogar con él sobre temas de política (G3). 


\section{La universidad: comunidad fundamental de recepción y de líderes de opinión}

En tanto, las chicas de clase media mencionaron con mayor frecuencia como líderes de opinión a integrantes de su familia, especialmente a sus papás (género masculino), situación que nos ayuda nuevamente a inferir que su condición de mujer las hace considerar a la familia $\mathrm{y}$, en especial, a los integrantes del género masculino como los conocedores de política y que tengan tanta confianza en ellos.

Mi papá siempre me decía que me informara, siempre me decía se vale informarse (G2).

Las universitarias de clase alta señalaron como líderes de opinión a sus padres y profesores. En este caso, es de importancia resaltar que además de la familia, la universidad también es otro de los espacios donde las jóvenes universitarias socializan.Es por ello que será en estos espacios donde reconozcan a sus líderes de opinión.

Cabe mencionar que todas las participantes de los tres grupos aclararon que las personas que ellas consideran líderes de opinión no influyeron en su voto, sino que sólo las ayudaron a poder pensar un poco más su decisión.

Bueno, mi papá no quería que cambiara mi voto, pero no influyó (G1).

También en mi casa, mi papá y sobre todo mi abuelita nos dijeron nadie de esta familia va a votar por tal candidato.Pero, en fin, yo pensé al fin y al cabo ya cuando esté en la casilla nadie me ve (risas) (G2).

\section{La televisión: el principal medio de información}

De acuerdo con el análisis, encontramos que el consumo de medios es una cuestión habitual en estas jóvenes, lo cual no es nada extraño en la actualidad, ya que este fenómeno no es ajeno a otros grupos sociales. También en el caso de las jóvenes universitarias, todas coincidieron en mencionar a la televisión como el medio por el cual se informan de política; en segundo lugar se encuentra la radio, y en tercero, con muy pocas menciones, el periódico.

\section{La credibilidad en los noticieros}

De los programas televisivos que ven, calificana los noticieros comolos más confiables en la emisión de información política; sin embargo, si bien estas jóvenes consideran que este medio es un referente para ellas, guardan siempre un margen de negociación con respecto a los mensajes que consumen.

\section{De su percepción de los spots televisivos}

La percepción general de las jóvenes universitarias con respecto a la propaganda política que se difunde es negativa. Las jóvenes coinciden en que el gasto que se hace en esta propaganda fue excesivo. 
En particular, con respecto a los spots televisivos, las jóvenes también tienen de manera general una opinión negativa. A pesar de que consideran que es necesario el uso de estos recursos publicitarios para conocer a los candidatos y sus propuestas, coinciden en que los gastos son excesivos y que por lo tanto debe ser más controlada la asignación de presupuesto para este rubro.

Creo que son necesarios los spots, pero no es necesario gastar tanto dinero (G3).

Yo siento que deberían establecer unas reglas, donde se les dé un porcentaje para todos por igual, y de ese porcentaje sacar todo lo que necesite (G1).

Deberían concientizar a la gente de los partidos, haciéndoles ver que los recursos que están gastando se pueden invertir en otras cosas más importantes(G3).

Las jóvenes universitarias pertenecientes a las tres clases sociales coincidieron en señalar que es muy importante la propaganda política que utilizan los candidatos, porque puede ser una ayuda a partir de la cual ellas puedan darse una idea de las propuestas que el contendiente realiza; es decir, para el caso exclusivo de estas mujeres jóvenes, sí juega un papel importante de referencia, mas no es determinante.

El que mete más publicidad es el que tiene más posibilidad de ganar (G1).

Pero sí despierta en ti una duda: ¿es cierto lo que están diciendo? Entonces ahora voy a investigar más, y poder tomar una decisión para dar bien mi voto (G3).

Sin embargo, mencionan que la influencia de un spotsobre sus decisiones va a depender de los conocimientos y convicciones que se tengan como persona.

Pero también depende de la mentalidad que uno tenga.Influirá en ti si te saben manejar, porque si tú tienes una idea sobre ese partido, de ahí ya no te van a sacar, y te cierras y dices pues no me importa, yo voto y yo voto $(\mathrm{G} 3)$.

\section{DISCUSIÓN Y CONCLUSIONES}

Como se puede observar este trabajo nos aporta información sobre cómo las jóvenes universitarias se relacionan con sus esferas, tanto pública como privada, a partir de su identidad de género; a partir de ello, nos da cogniciones sobre la percepción y el papel que los spots políticos televisivos ejercieron en la decisión electoral de las jóvenes universitarias.

Para poder entender cómo construyen las jóvenes universitarias el ejercicio de su participación política a partir de su proceso de recepción de los de los spots políticos televisivos, es necesario saberprimero cómo perciben su identidad, ya que estas jóvenes mantienen una doble condición: la de ser mujeres y la de ser jóvenes. La condición que prevalece y a partir de la cual trazan su identidad es la de ser joven, antes de su identidad como mujer.

En el trabajo expuesto se evidencia que su identidad juvenil les permite quese conciban como personas con pocas responsabilidades y preocupaciones, en comparación con las mujeres adultas, ya que relacionan responsabilidad y preocupación con el no tener que criar 
y cuidar hijos, no estar a cargo de las diversas actividades domésticas, no tener que atender a un esposo. Esto les permite sentirse independientes y libres de ejercer ciertas actividades.

Las mujeres jóvenes siguen vinculadas al espacio privado, derivado de las desigualdades que aún existen en los ámbitos de agregación y de reconocimiento laboral, político e histórico, situación que no ha permitido el acceso total al espacio público para las jóvenes mujeres, pese al reconocimiento de las transformaciones sociales que se han producido en los últimos tiempos.

Por lo tanto, tal ocupación del espacio privado permite que se siga generandoun apego a la familia (Fernández, 2003), y que independientemente de que no tengan hijos o esposo, sepreocupan y se sienten responsables de los demás, característica de su condición de mujeres. A partir de esta investigación se demuestra que laesfera doméstica se constituye como un espacio importante de socialización y construcción de ideas de las jóvenes mujeres.

En tanto que estas mujeres jóvenes cursan estudios de nivel superior, la universidad se constituye como otro espacio donde pasan gran parte de su tiempo y, por lo tanto, genera un impacto en su desarrollo como personas. Hemos visto que la universidad, como esfera pública, es el espacio donde tienen la oportunidad de vincularse en una relación de construcción del conocimiento;donde socializan en torno a valores, costumbres, concepciones del mundo, teorías y posturas del conocimiento y su papel en la sociedad. Todo este cúmulo de conocimientos y acervo cultural que obtienen como estudiantes, las hace sentirse diferentes de otras mujeres; se perciben seguras de sí mismas, porque en un futuro tendrán la posibilidad de una independencia económica. Además se sienten con la confianza de emitir sus opiniones; eso sí, tomando en cuenta siempre la aprobación del sexo masculino y adulto.

En un intento por develar las características de las mujeres jóvenes universitarias como nuevas votantes, se ha encontrado que las participantes de este estudio tienen una percepción negativa de la política; la definen como conflictiva, deshonesta, que no cumple con su función principal: la de ayudar a los demás.

A estas jóvenes les gusta hablar y hacer consultas sobre política con su familia; específicamente, con su padre, hermanos y abuelos.Jamás mencionan a una persona del sexo femenino, por lo que cuando de política se trata, recurren a aquéllos que consideran conocedores del tema. Esto resulta una situación lógica si partimos de la idea de que a pesar de que estas jóvenes pertenecen o tienen determinado acceso a la esfera pública, buscan en la figura de los varones un reconocimiento de sus opiniones.

Asimismo, en esta investigación se ha demostrado que la universidad seconstituye como uno de los agentes principales de socialización política de las mujeres jóvenes universitarias.Es por ello que no resulta sorprendente que sea un lugar donde suelen hablar de política,ya que lo consideran un espacio que les da la posibilidad de dialogar con sus grupos de pares: amigos y compañeros de clase con quienes comparten sus intereses y necesidades que exigen de la política y de quienes la ejercen como jóvenes. Además, esta investigación permite señalar que las mujeres jóvenes universitariasacuden a sus profesores - en masculino-para consultarlos y tomar como referencias sus opiniones de la actividad política. En este caso, se puede mostrar quela universidad es la institución que se dibuja como el punto de intersección entre la esfera privada yla esfera pública de estas mujeres.

El discurso de las jóvenes universitarias que aquí se ha analizado, permite mostrar la percepción que tienen de los spots televisivos.

De acuerdo a los resultados de esta investigación, si bien los spots políticos televisivos fueron necesarios para que las mujeres jóvenes universitarias conocieran a los candidatos y 
sus propuestas, finalmente para estas jóvenes los mensajes no cumplen con la función de dar a conocer propuestas. Coinciden en que el gasto destinado para la propaganda política televisiva es excesivo, situación que desde su perspectiva debe regularse para las campañas.

En cuanto a cómo se allegan de información, la televisión es un medio proveedor de información para las mujeres jóvenes universitarias nuevas votantes en México, pero especialmente es el medio de comunicación al que más recurren para allegarse de información referente a la política. Es verdad que también recurren a la radio e internet - especialmente, las jóvenes de mayores recursos - y la prensa, en menor medida, pero en sí la televisión se coloca como prioritaria.

Las jóvenes universitarias primeras votantes consideran importante la propaganda política televisiva, ya que ésta les ayuda a conocer de manera concretaparte de laspropuestas de los candidatos; es decir, se constituye como una referencia que las invita a conocer y seguir más de cerca las actividades políticas del contendiente.

Sin embargo, consideran que para que un spot político televisivo pueda llamar su atención es necesario que contenga un mensaje de propuestas que contemplen las necesidades que tienen primero como jóvenes y luego como mujeres. Esto apunta a la percepción que tienen de su identidad juvenil antes de su identidad femenina. Las propuestas que estas jóvenes esperan escuchar se centran especialmente en oportunidades de empleo y de educación, y después, aquellas referentes a la seguridad osalud, aspectos que tienen presentes por su identidad femenina. Cuando se sienten excluidas, no tomadas en cuenta, al no considerar temáticas de su interés, entonces perciben a los spots aburridos y sin contenido.

De acuerdo con esta investigación, a pesar de que a las jóvenes universitarias les pueda agradar tanto el candidato como sus propuestas en el spot político, este factor nos las lleva a emitir un voto, porque entonces su percepción y forma de pensar como nuevas votantes se impone,por lo que solicitan otras opiniones que las ayuden a consolidar un buen ejercicio de su ciudadanía.

Su identidad como mujeres, como jóvenes y como universitarias, delinea cómo reciben los mensajes políticos que les brinda la televisión. Son también factores de influencia su estrato socioeconómico, la carrera y la universidad donde estudian.

Todos estos aspectos muestran que el proceso de recepción televisiva de las mujeres jóvenes universitarias primeras votantes se traduce en un proceso activo y con diversos factores que median el mensaje.

Entonces, se puede apuntar que los spots políticos televisivos no tienen un papel determinante en la decisión electoral de las mujeres jóvenes universitarias.

La recepción de estos spots políticos siempre se vio interferida por diversas mediaciones que conforman el contexto en el que se constituyen las jóvenes universitarias.

Llegar a estas conclusiones nos acerca a otro punto de partida para nuevos trabajos. Las mujeres jóvenes universitarias son figuras de las cuales se sabe poco.Por lo tanto, la conclusión que a partir de ello desprendemos es la necesidad de seguir tejiendo trabajos de investigación que nos permitan continuar avanzando en el estudio de este fenómeno. 


\section{Referencias}

Aramburu Ceñal, C. "Aproximaciones a mujer joven y mercado de trabajo" en Revista de Estudios sobre la Juventud CREA, nueva época, No. 4, septiembre/diciembre de 1984.

Beauduox, V. (2005). Comunicación Política y Campañas Electorales. Gedisa. España.

Brito, R. (2002). "Identidades juveniles y praxis divergente; acerca de la conceptualización de juventud" en Nateras Alfredo, Jóvenes, culturas e identidades urbanas pp. 44-59.

Bustos, O. (1999). "Impacto y percepción en adolescentes (de ambos sexos) y madres de familia, de los mensajes e imágenes proyectados en telenovelas" en Estudios de género y feminismo I. Distribuciones Fontamara, pp. 21-47.

Bustos, O. (1992). "Mujeres y participación política" en G. Mota Botello (coord.), Cultura Política: un enfoque psicosocial. UNAM-CRIM (Aporte de investigación, núm. 42, Cuernavaca.

Chaín, R. (1995). Estudiantes universitarios, Trayectorias escolares, Universidad Veracruzana, Universidad Autónoma de Aguascalientes, México.

Dávila, O., Ghiardo, F. (2005). Trayectoria de Vida y nuevas condiciones juveniles. Santiago de Chile.

De Garay, Adrián, Casillas, M. (2002). "Los estudiantes como jóvenes. Una reflexión sociológica" en Nateras Alfredo, Jóvenes, culturas e identidades urbanas pp. 245-262.

De Garay, A. (2003). Una mirada a los jóvenes universitarios mexicanos en José Antonio Pérez Islas y otros (Coord), Nuevas miradas sobre los jóvenes. México-Quebec. Colección Jóvenes no. 13. México.

Durkin, K. (1985). Television, Sex Roles and children, Open University Press, Syracuse, Nueva York.

Ehrenfeld N., Fernández H, (2003). La generación Joven al principio del siglo XXI, en José Antonio Pérez Islas (Coord), Jóvenes Mexicanos del Siglo XXI. Encuesta Nacional de Juventud 2000, SEP/IMJ/CIEJ, México.

Ehrenfeld Lenkiewicz, N. (2003). Los jóvenes y las familias. Encuentros y tensiones entre filiaciones e identidades, en José Antonio Pérez Islas y otros (Coord), Nuevas miradas sobre los jóvenes. México-Quebec. Colección Jóvenes no. 13. México.

Fernández Poncela, A. M. (2005). Cultura Política y Jóvenes en el Umbral del Nuevo Milenio. Colección JovenEs. Núm. 12. IFE e Instituto Mexicano de la juventud.

Franco, Bolívar. (2000). Centroamérica y Panamá: movimientos sociales juveniles y proyecciones hacia el nuevo siglo. Elementos para el debate (1996).La participación social y política de los jóvenes en el horizonte en el nuevo siglo. Colección Grupos de Trabajo de CLACSO. Consejo Latinoamericano de Ciencias Sociales. Buenos Aires, Argentina.

Grandi, R. (1995). Texto y contexto en los medios de comunicación Análisis de la información, publicidad, entretenimiento y su consumo. Barcelona. Bosch.

Gurrieri, A., Torres-Rivas E. (1971). Situación de la juventud dentro del complejo económico-social de América Latina, al Estudios sobre la juventud marginal latinoamericana. Santiago. Siglo XXI.

Jensen, K. (1992). El análisis de la recepción: la comunicación de masas como producción social de significado, en Jensen K, y Jankowski, N. (Ed.), Metodologías cualitativas de investigación en comunicación de masas, Barcelona, Bosch.

Jensen, K. B y Rosengren. (1987). Five Tradicions in Search of the Audience, Communications Research in Europe: the State of the Art, en European Journal of Communication.

Kaid, L. (2001). Videostyle in Presidencial Campaigns. Praejer Publishers USA.

Lagarde M. (2007) Entrevista por Cob Gabriela y Francia Fernando. Habitación propia, espacio Encuentro de Jóvenes. [La edad más densa de las mujeres] http://cosmovisiones.com/habitacionpropia/cont/lagarde.html, Costa Rica, Recuperado el 4 de febrero.

Lamas, M. (2000). Cuerpo: diferencia sexual y género. Taurus, México.

Lull, J. (1990). Recepción televisiva, reforma y resistencia en China. 
Lull, J., Sun, S.W. (1988). Agent of modernization: television and urban Chinese families. En J. Lull (ed.), World families watch television, Newbury Park, California, Estados Unidos, Sage Publications, pp. 193-236.

Martín Barbero, J. (1987). De los medios a las mediaciones: comunicación, cultura y hegemonía. México. Gustavo Gili.

Miranda López, F. (2002). Transición educación mercado de trabajo en jóvenes, en José Antonio Pérez Islas (Coord), Jóvenes Mexicanos del Siglo XXI. Encuesta Nacional de Juventud 2000, SEP/IMJ/CIEJ, México.

Morley, D. (1980). The Nationwide Audience, Londres, British Film Institute

Morley, D. (1996). Televisión audiencias y estudios culturales, Amorrortu, Buenos Aires.

Orozco (comp) Hablan los televidentes. Estudios de recepción en varios países, México, Universidad Iberoamericana, pp. 75-96.

Orozco, G. (1996). La TV a fin de milenio: un medio poderoso, cuyo límite es la audiencia, Cuadernos del PROIICOM, México D.F., No.2.

Orozco, G. (1996). Televisión y audiencias. Un enfoque cualitativo, México: Universidad Iberoamericana/Ediciones de la Torre.

Orozco, G. (1987). Televisión y producción de significados: tres ensayos. Serie Cuadernos de Comunicación y Sociedad No. 2, CEIC, México.

Portillo, M. (2003). Revisión en línea, Revista de Estudios sobre Juventud. Julio-Diciembre. Juventud y Política. Representaciones en el discurso de los jóvenes de la ciudad de México JOVEN es. http://imjuventud.gob.mx/pdf/rev_joven_es/19/Juventudypol\%EDtica,MaricelaPortillo.pdf Año 7, núm. 19 México, D.F, pp.220-245. Recuperado el 4 de Febrero de 2006.

Ramos, J., Jiménez S., et. (2000). "Primer encuentro redefinió las Tácticas en las campañas", El Universal. México, 6 de Junio.

Reguillo Cruz, R. (2000). Emergencia de culturas juveniles. Estrategias del desencanto. Buenos Aires: Grupo Editorial Norma.

Reguillo Cruz, R. (2002). Jóvenes y Esfera Pública, en José Antonio Pérez Islas (Coord), Jóvenes Mexicanos del Siglo XXI. Encuesta Nacional de Juventud 2000, SEP/IMJ/CIEJ, México.

Silverstone, R. (1996). Televisión y vida cotidiana. Buenos Aires, Argentina. Amorrortu Editores.

Vega, A. (2005). Razón y Palabra Octubre- Noviembre [Los escenarios de la Comunicación Política Mexicana] http://razonypalabra.org.mx/anteriores/n35/avega.html en No. 35. Recuperado en 05 Junio del 2006.

Vega Montiel, A. (2004). Comunicación política y democracia: un desafio para nuestra participación Tecnológico de Monterrey, Nova Iuris.

Villamil, J. (2006) “Televisa: venga más”, Proceso, México, No. 1545, 11 de Junio, pp. 22-26.

Zuckermann, L. (2006) El Universal on line, 22 Febrero, [Muchos spots, pocos cambios] http://www.eluniversal.com.mx , Recuperado el 29 de Marzo.

\section{Sobre la Autora}

Nuria Beatriz Peña Ahumada: Licenciada en Comunicación por la Universidad Autónoma de Querétaro, Maestra en Comunicación por la Universidad Mesoamericana y Candidata a Doctora en Administración por la Universidad de Celaya. Actualmente es Profesora de Tiempo Completo de la Universidad Tecnológica de San Juan del Río, donde imparte asignaturas de Publicidad, Estudio del Consumidor, Metodología de la Investigación. Autora de artículos y ponencias referentes al impacto de los spots y marketing político, recepción televisiva y audiencias. Presidenta de la Red Nacional de Cuerpos Académicos de la División de Negocios de las Universidades Tecnológicas en México. 